\title{
Abnormal fatty acid composition and human atherosclerosis
}

\author{
K. J. Kingsbury, C. Brett, R. Stovold, A. Chapman, \\ J. Anderson, D. M. Morgan \\ St Mary's Hospital, London, W.2
}

\begin{abstract}
Summary
Eighty patients with aorto-iliac/ femoro-popliteal atherosclerosis were collected to examine in detail their plasma cholesteryl ester fatty acid compositions and to compare them with the incidence of ischaemic heart disease through a 4-year follow-up. Various other biochemical and rheological parameters were also measured to see if these might explain any association between the abnormal fatty acid pattern and ischaemic heart disease.

The abnormal fatty acid pattern was specifically and generally similar to that found in essential fatty acid (EFA) deficient animals and children as shown by the increase of the specific trienoic acid (C.20:3 : $\omega 9)$ by reduced linoleic acid concentrations, and by an increase of C.18 and C.16 monoenoic acids (oleic and palmitoleic), but not of their corresponding saturated forms, stearic and palmitic. The results suggest that the abnormal fatty acid composition resulted from an increased synthesis of monoenoic acids and monounsaturase activity, coupled with a relative inadequacy of linoleic acid.
\end{abstract}

The patients with a reduced concentration of linoleic acid $(<35 \%)$ subsequently had a higher incidence of myocardial infarction. No significant correlations were found between the fatty acid concentration and various other biochemical or rheological parameters except marginally between linoleic acid and platelet adhesiveness. Only the linoleic acid concentration distinguished between the patients with and without myocardial infarction.

A marked inverse correlation was found, however, between the monoenoic and linoleic acid concentration, without parallel changes in other fatty acids. It seems that as in animals, a balance exists between EFA and monoenoic pathways which are known to compete for the same desaturase systems and acyl sites. It appears that human EFA requirements and effects need to be considered not only by their intake and metabolism, but also through individual factors which vary the monoenoic concentrations and monounsaturase activity. Since these factors include several currently associated with human atherosclerosis the question arises of whether the EFA-monoenoic balance is one

Correspondence and requests for reprints: K. J. Kingsbury, 11 South Road, Amersham, Bucks. link between them and the pathology of the arterial occlusions and myocardial infarction.

Introduction

A reduced concentration of linoleic acid in the plasma cholesteryl esters is one biochemical abnormality found in patients with ischaemic heart disease (Lewis, 1958), or aorto-iliac/femoro-popliteal atherosclerosis (Schrade, Böehle and Biegler, 1960; Kingsbury et al., 1962b). It also occurred in the depot fats of similar patients (Kingsbury et al., 1962b; Antonini et al., 1969). Since the depot fat composition varied little with the site sampled (Kingsbury et al., 1961 ; Heffernan, 1963), it appeared that these patients had a widespread reduction of linoleic acid in their body fats.

It was not known if this abnormality was related to the arterial disease, or was simply an associated but unimportant phenomena. The eventual classification of the arterial lesions in terms of their mural irregularities, occlusions and stenoses (Kingsbury, 1969), revealed that the plasma cholesteryl linoleic acid concentrations but not the plasma cholesterol or blood sugar levels were related to the number of arterial occlusions shown by arteriograms or pulses (Kingsbury et al., 1969a). This appeared important to the patient since those with the low linoleic acid concentrations then showed a marked rise in the subsequent incidence of myocardial infarction at all disease levels (Kingsbury et al., 1969b). In contrast, no separate relation was found between the plasma cholesterol or blood sugar levels and myocardial infarction when the extent of the arterial disease was taken into account (Kingsbury, 1969; Kingsbury et al., 1969b).

To investigate the abnormal fatty acid composition in more detail three studies (Lewis, 1958; Kingsbury et al., 1962b; Kingsbury et al., 1969a) had reported an increase of trienoic fatty acids (fatty acids with three unsaturated bonds) together with the reduction of the dienoic-linoleic acid. This combination also occurred in animals and children deficient of essential fatty acids (Wiese, Hansen and Adam, 1958; Holman, 1968); in which case the increased trienoic acid was a specific isomer synthesized from oleic acid (Fulco and Mead. 1959). It appeared crucial to see which trienoic acid was responsible for the particular increase in the patients. 
TABLE 1. Ages, plasma cholesterol, and 2-hr blood sugar levels and $\%$ of patients in the irregularity and occlusion groups in previous and present series of patients

\begin{tabular}{|c|c|c|c|c|c|c|c|c|c|c|}
\hline \multirow{3}{*}{ Series of patients } & \multirow[b]{3}{*}{ No. } & \multicolumn{3}{|c|}{ Mean values \pm standard errors } & \multicolumn{6}{|c|}{$\%$ of patients in groups } \\
\hline & & \multirow{2}{*}{$\begin{array}{c}\text { Age } \\
\text { (years) }\end{array}$} & \multirow{2}{*}{$\begin{array}{c}\text { Plasma } \\
\text { cholesterol } \\
(\mathrm{mg} / 100 \mathrm{ml})\end{array}$} & \multirow{2}{*}{$\begin{array}{l}\text { 2-hr blood } \\
\text { sugar } \\
(\mathrm{mg} / 100 \mathrm{ml})\end{array}$} & \multicolumn{3}{|c|}{ Irregularity } & \multicolumn{3}{|c|}{ Occlusions } \\
\hline & & & & & Slight & Moderate & Extensive & 0 & 1 & $>2$ \\
\hline Previous series (a) & 338 & $59 \pm 0 \cdot 54$ & $260 \pm 3 \cdot 12$ & $107 \pm 3 \cdot 52$ & 36 & 36 & 28 & 29 & 41 & 30 \\
\hline & 146 & $57 \pm 0.49$ & $262 \pm 6.09$ & $105 \pm 3.01$ & 38 & 38 & 24 & 28 & 43 & 29 \\
\hline Present series & 80 & $59 \pm 0.92$ & $255 \pm 5 \cdot 26$ & $101 \pm 5 \cdot 19$ & 42 & 39 & 19 & 35 & 36 & 29 \\
\hline
\end{tabular}

(a) Kingsbury, 1966; (b) Kingsbury et al., 1969a, b.

Gas-liquid chromatographic techniques had first to be developed which could separate and measure the different trienoic acids (some in trace quantities) directly and routinely. This then allowed the following questions to be examined: (a) which trienoic acids increased, did they represent a particular metabolic pathway? (b) what were the main features of the abnormal fatty acid pattern, and (c) which part showed the clearest relation to the subsequent occurrence of myocardial infarction and various other parameters, e.g. platelet adhesiveness, fibrinolysis, etc. The results are reported here.

\section{The patients}

\section{Collection}

Eighty* male patients presenting with claudication from aorto-iliac/femoro-popliteal atherosclerosis, who had not recently altered their diet, were not receiving drugs and had not had symptoms of heart disease were collected as previously described (Kingsbury, 1971). As shown in Table 1 their ages, plasma cholesterol, '2-hr' blood sugar concentrations (Kingsbury, 1968), and the extent and type of their disease, were similar to those of previous series (Kingsbury, 1968; Kingsbury et al., 1969a). The proportion of patients with extensive arterial irregularities (Kingsbury, 1971) was slightly, though not significantly, lower than had been found previously.

\section{Sampling and experimental design}

The plasma cholesteryl linoleic acid concentrations of the eighty patients had been determined using alkaline conjugation when the patients attended for their initial arteriograms. The samples for the analyses of the present study were then collected during a planned experimental period in which three patients were sampled on each of 3 mornings a week, on mornings convenient to them, but in the rough order of their first attendance at hospital, and

\footnotetext{
* This number had to be collected before there were at least two patients in each irregularity by occlusion disease category (data with K.J.K.).
}

making sure that each morning included patients whose linoleic acid concentrations were in the upper and lower halves of the group range. Blood samples were taken by clean venepuncture without venous compression after the patients had fasted overnight; the first $5 \mathrm{ml}$ was discarded. All parameters were estimated from the same fasting blood samples except the blood glucose which was analysed in a sample collected $2 \mathrm{hr}$ after $50 \mathrm{~g}$ of glucose by mouth.

\section{Methods $\dagger$}

Fatty acid composition of plasma cholesteryl esters $\ddagger$

The plasma was extracted with solvents and the cholesteryl esters isolated by silicic acid chromatography (Kingsbury et al., 1969a) on the day of collection together with a solvent blank and normal plasma as controls. The prepared cholesteryl esters contained no glycerides, lipid phosphorus, or free cholesterol as shown by thin-layer chromatography and colorimetric tests. Completeness of isolation was confirmed by examining the lipids remaining on the column (methanol-chloroform eluate) by thin-layer chromatography. The ferric chloride colour (Henly, 1957), between 300 and $580 \mathrm{~m} /$, showed that no other sterol peaks were present. The concentration of cholesteryl ester in the final solution was determined from both the cholesterol and esterified fatty acid content.

The cholesteryl fatty acid composition was then estimated in three ways.

\section{(1) Thick-layer chromatography}

The preparations of the previous day were run on thick silicic acid fluorescein layers, each divided longitudinally into halves, one half containing $5 \%$ silver-nitrate. Equal aliquots from each patient's sample were run in each half simultaneously $(2 \%$ diethylether in petroleum ether $\left.40-60^{\circ} \mathrm{BP}\right)$. This was

† The standard deviations given for each method were calculated from the differences between the replicate estimations of the samples in this study.

† Fatty acid notation as usual: C.20 equals 20 carbons, : 3 equals three unsaturated bonds, and $\omega 9$ means that the first unsaturated bond occurred after the ninth carbon from the methyl end of the fatty acid chain. 
repeated giving two plates per patient. The monoenoic and dienoic ester bands separated on the silver-nitrate, and the total cholesteryl ester band from the plain half of the plate, were scraped off under UV light, and the amount of esters they contained determined from their cholesterol content (Henly, 1957).

This provided an estimate of fatty acid composition without using any form of fatty acid analysis. The results are expressed as \% dienoic esters in cholesteryl ester fraction (standard deviation: $\pm 1.22 \%$ ) and ratio of monoenoic to dienoic ester amounts (standard deviation: $\pm \mathbf{0} \cdot 018$ ).

\section{(2) Alkaline conjugation}

As summarized previously (Kingsbury et al., 1969a), this provided the total of each polyunsaturated fatty acid class against which the amounts of the individual components, determined by gas-liquid chromatography (GLC), could be checked.

The samples were conjugated (Holman and Hayes, 1958) the day after collection, in batches of twelve per run-three subject samples, one solvent blank (from extraction and column), one bulked normal plasma, and a conjugation standard of diluted cod liver oil, each in duplicate. The highest and lowest dienoic acid values in each run were checked again at the end of the series. The UV absorption peaks of the patients' samples were compared with cholesteryl esters from normal controls: no unusual peaks were found. The percentage of dienoic (standard deviation: $\pm 1.08 \%)$, trienoic $( \pm 0.14 \%)$ and tetraenoic acids $( \pm 0.22 \%)$ are considered here.

\section{(3) Gas-liquid chromatography (GLC)}

Automated gas-liquid capillary* chromatographic techniques $\dagger$ were developed to separate and measure directly the fatty acids between $\mathrm{C} .11$ and $\mathrm{C} .23$ saturated external markers, including the two C.18 and the three C.20 trienoic acid isomers. Replicate analyses of normal samples had established a consistent fatty acid pattern, and demonstrated that the smaller peaks were not artefacts. The identities and retention times of the peaks had been determined precisely by overlaying them with methyl ester standards $\ddagger$ (including the C.18 and C.20 trienoic acid) and natural samples $\ddagger$ (including the fats from EFA deficient rats) on four different polar capillary columns* which varied the relative positions of the saturated and unsaturated fatty acids. The identity

\footnotetext{
* Perkin Elmer Ltd.

† Perkin Elmer Ltd-F.11, Parametric Amplifier, Infotronics C.R.S. 100 integrator. Honeywell Mark III Computer, G.P.O. Terminal System.

‡ Standards obtained from: The Hormel Institute, Applied Science Laboratories, Sigma Ltd. Professor Van Dorp, Unilever Laboratories, Vlaardingen.
}

of the peaks in the cholesteryl ester samples allocated as C. $20: 3 \omega 6$ and C. $20: 3 \omega 9$ in the C. 20 : $3 \omega 9$ and C. $20: 2 \omega 6$ area had been confirmed by mass spectroscopy§. No differences were found between the quantitative response of the three different C. $20: 3$ or between the two C.18: 3 trienoic acid isomers (calculated by triangulation or integration) when mixtures of equal amounts were injected into the columns. Hence, any difference between them in the patients' samples would not appear due to differences in detector response or to losses on the columns. The method studies will be published in full elsewhere.

Low then high trienoic acid samples (to be described), a bulked normal plasma, and a mixed standards were run in sequence $\mathbf{9}$. A run of the mixed standards is shown in Fig. 1.

The carbon numbers and percentage composition of all peaks, identified by their exact retention times and areas, were calculated by computer programme using the known C.14, 16 and 18 internal and the C.11 and C.23 external markers to establish the logtime-mass curve for each sample (to be published). The fit of all retention times to the standard curve was good (index of determinations all greater than 0.996).

For every sample the emergence time of all peaks (as shown by the integrator and used and printed out by the computer) was written over each peak as it appeared on the trace. In this way, there could be no question of which area and percentage composition applied to which peak.

The coefficient of variation $(\mathrm{CV})$ determined for all peaks from the differences between the replicate estimations varied with peak size. For fatty acids in concentrations over $5 \%$ the CV was less than $2 \%$, from $1 \%$ to $5 \%$ concentration the $\mathrm{CV}$ was less than $7 \%$ and under $1 \%$ concentration, the $\mathrm{CV}$ of the majority was less than $10 \%$.

\section{Other analytical methods}

Other parameters were estimated as follows: plasma cholesterol by modification of Henly's procedure (1957) (standard deviation: $\pm 5.31 \mathrm{mg} / 100$ $\mathrm{ml}$ ), blood sugar by glucose oxidase method (Huggett and Nixon, 1957) $( \pm 2.86 \mathrm{mg} / 100 \mathrm{ml})$, platelet adhesiveness (Hirsh, McBride and Wright, 1966) $( \pm 2.25 \%)$, fibrinogen concentration (Podmore, 1959) ( $\pm 16 \mathrm{mg} / 100 \mathrm{ml}$ ), fibrinolysis (Gallimore, 1967) ( $\pm 0.18 \mathrm{hr}$ ), platelet and red cell electrophoretic mobility (Bangham et al., 1958) in buffer

\footnotetext{
$\S$ Dr W. Kelly, Unilever Ltd, Colworth.

9 Perkin Elmer $50 \mathrm{~m}$ capillary FFAP column, isothermal at $205^{\circ} \mathrm{C}$. Flow rate, $\mathrm{O}_{2}$ free nitrogen, $0.8 \mathrm{ml} / \mathrm{min}$ : split $80: 1$. Baseline variation $<0.2 \%$ of recorder span.

Injection $5 \mu \mathrm{l}$ ethyl benzene solution of $\mathrm{CE}$ containing $5 \mu \mathrm{g} \mathrm{C.11}$ and C.23 external markers. Plate values for methyl arachidate over 60,000 .
} 


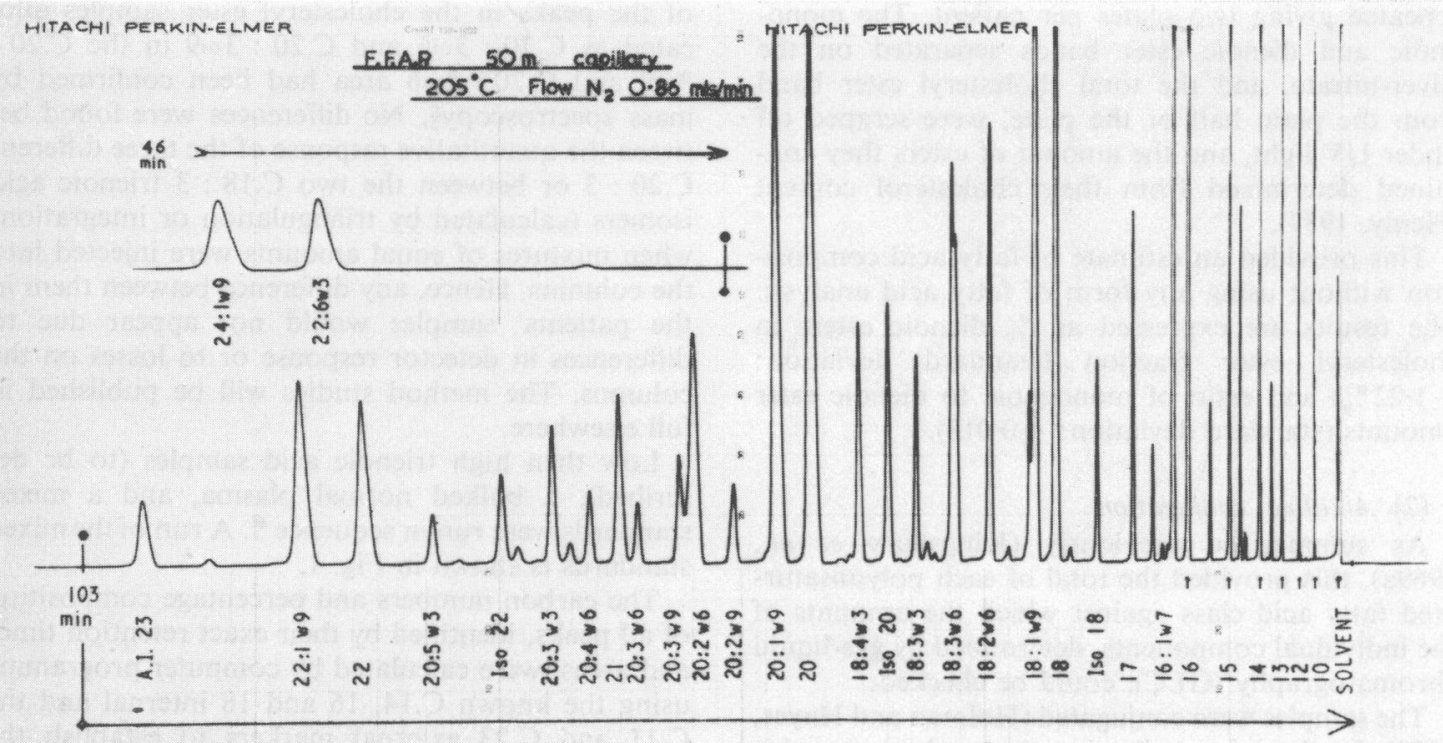

FIG. 1. A tracing of mixed standards of pure methyl fatty acid esters run in the column and conditions used for the patients' samples.

(Heard and Seaman, 1960) $( \pm 0.057 \mu / \mathrm{secv})$; platelet count, ESR (Westergren) and haematocrit (Wintrobe) were performed by standard methods, and relative viscosity of the plasma was estimated by Ostwald viscometer (Findlay, 1954).

\section{Follow-up}

The patients were followed until the fifth year after their first appearance at hospital (Surgical Unit, St Mary's Hospital, London) by contact with the patients, their relatives, General Practitioners, the various hospitals they attended and Executive Councils.

The Practitioners' reports, their replies to an annual standard questionnaire on health, complications and treatments, the hospital records, laboratory investigations, arteriograms and ECGs were collated for all patients together with the death certificates and post mortem reports where appropriate.

Four prognostic groups emerged as in a previous study (Kingsbury et al., 1969a). These were: (a) alive without symptoms of heart disease (forty); (b) angina of effort without myocardial infarction (eleven); (c) non-fatal acute myocardial infarction with or without angina of effort (fourteen) and (d) fatal infarcts, myocardial (twelve), cerebral (one), which as previously was the major cause of death in these patients (Kingsbury, 1966; Kingsbury et al., 1969a).

The presence or absence of symptoms of heert disease was diagnosed clinically by their General Practitioners and/or the doctors of the hospitals they attended and checked with the patients, their rela- tives, Practitioners, the various hospitals, ECGs $\overrightarrow{0}$ death certificates and post mortem reports a\& $\perp$ necessary.

There were two 'non-vascular' deaths, one car cinoma of the lung and one from renal failure, the analyses on these two patients are not included in the results related to prognosis.

Angina of effort without myocardial infarction so far (eleven). Subsequent ECGs were available in all these patients, seven showed significant ST changes (Blackburn et al., 1960), reported as ischaemia. One showed QRS changes reported as infarct. Three showed no ECG abnormality.

Non-fatal acute myocardial infarcts, with or without angina of effort (fourteen). ECGs were available in all. These showed significant QRS changes (Blackburn et al., 1960) in thirteen, reported as infarcts. One showed only ST changes reported as ischaemia. Four of these patients have had more than one non-fatal myocardial infarct since 1967.

Fatal infarcts. The cerebral infarct was confirmed at post mortem. Of the twelve fatal myocardial infarcts, four were confirmed both by ECG and post mortem, three by ECG alone and one by post mortem alone. Subsequent ECGs or post mortems were not undertaken in four patients: there appeared no doubt, however, that death was preceded by the characteristic symptoms of acute infarction.

\section{Results}

Low and high trienoic acid containing samples

The total trienoic acid concentrations in the plasma cholesteryl esters of all eighty patients were estimated 
TABLE 2. A comparison of the low and high trienoic acid samples by the parameters common to the three different methods of fatty acid analysis (means with their standard errors in parentheses)

\begin{tabular}{|c|c|c|c|c|c|}
\hline \multirow{2}{*}{\multicolumn{2}{|c|}{ Fatty acid }} & \multirow[b]{2}{*}{ Method } & \multicolumn{2}{|c|}{ Sample } & \multirow{2}{*}{$\begin{array}{l}\text { Correlation between } \\
\text { different methods } \\
\text { (correlation } \\
\text { coefficients) }\end{array}$} \\
\hline & & & $\begin{array}{l}\text { Low } \\
\text { trienoic }\end{array}$ & $\begin{array}{l}\text { High } \\
\text { trienoic }\end{array}$ & \\
\hline \multicolumn{2}{|c|}{$\begin{array}{l}\text { Total } \\
\text { trienoic }(\%)\end{array}$} & $\begin{array}{l}\text { Conjugation } \\
\text { GLC }\end{array}$ & $\begin{array}{l}1.48(0.12) \\
1.68(0.06)\end{array}$ & $\begin{array}{l}3 \cdot 32(0 \cdot 17) \\
2 \cdot 94(0 \cdot 13)\end{array}$ & +0.69 \\
\hline \multicolumn{2}{|c|}{$\begin{array}{l}\text { Total } \\
\text { dienoic } \\
(\%)\end{array}$} & $\begin{array}{c}\text { Plate } \\
\text { Conjugation } \\
\text { GLC }\end{array}$ & $\begin{array}{ll}45 \cdot 7 & (1 \cdot 37) \\
43 \cdot 0 & (1 \cdot 12) \\
42 \cdot 6 & (1 \cdot 29)\end{array}$ & $\begin{array}{ll}35.9 & (1 \cdot 69) \\
34 \cdot 7 & (1 \cdot 25) \\
34.2 & (0.66)\end{array}$ & $\left.\begin{array}{l}+0.66 \\
+0.69\end{array}\right\} 0.64$ \\
\hline \multicolumn{2}{|c|}{$\begin{array}{l}\text { Total } \\
\text { tetraenoic }(\%)\end{array}$} & $\begin{array}{c}\text { Conjugation } \\
\text { GLC }\end{array}$ & $\begin{array}{c}4 \cdot 88(0 \cdot 13) \\
4 \cdot 43(0 \cdot 24)\end{array}$ & $\begin{array}{l}4 \cdot 49(0 \cdot 19) \\
4 \cdot 25(0 \cdot 28)\end{array}$ & +0.72 \\
\hline \multicolumn{2}{|c|}{$\begin{array}{l}\text { Total } \\
\text { mono/dienoic }\end{array}$} & $\begin{array}{l}\text { Plate } \\
\text { GLC }\end{array}$ & $\begin{array}{l}0.59(0.04) \\
0.56(0.03)\end{array}$ & $\begin{array}{l}0.90(0.10) \\
0.88(0.05)\end{array}$ & +0.85 \\
\hline GLC & $\begin{array}{l}\text { Total m } \\
\text { Total di } \\
\text { Total tri } \\
\text { Total te }\end{array}$ & $\begin{array}{lr}\text { oenoic } & \text { sum } \\
\text { oic } & \text { sum } \\
\text { oic } & \text { sum } \\
\text { enoic } & \text { sum } \\
& \text { Fatty a }\end{array}$ & $\begin{array}{l}4: 1 \omega 5,15: \\
8: 2 \omega 6,20: \\
8: 3 \omega 6,18: \\
0: 4 \omega 6 . \\
\text { otation as shc }\end{array}$ & $\begin{array}{l}16: 1 \omega 7,17 \\
6 . \\
3,20: 3 \omega 9, \\
\text { on Ta ble } 3 \text {. }\end{array}$ & $\begin{array}{l}18: 1 \omega 9,20: 1 \omega 9 . \\
3 \omega 6 .\end{array}$ \\
\hline
\end{tabular}

by alkaline conjugation. The values showed a normal distribution with a mean of $2 \cdot 27 \% \%^{*}$ The samples with the lowest $(<1.78 \%)$ and highest $(>2 \cdot 18 \%$ ) quarter of values were selected so that by contrasting their fatty acid compositions the nature of the trienoic acid increases and the features of the abnormal fatty acid composition could be determined.

The differences between these two groups were checked by comparing results common to the different methods (Table 2).

Table 2 shows that the values obtained by the different methods compared well (no significant differences), inter-correlations were high (correlation coefficients greater than $0.6, P<0.01$ ); and the differences between the two groups were consistent. Since the total monoenoic and trienoic acids determined by gas-liquid chromatography were calculated from the sum of several component acids, it appeared that significant amounts were not being missed. The agreement between the results of the different methods showed that the allocation of samples into high and low trienoic acid groups was valid and could be accepted as the basis for the detailed analyses.

\section{The nature of the trienoic acid increases}

The two C.18 and three C.20 trienoic acid peaks and their parent acids are illustrated on a GLC trace of a 'high' trienoic acid sample in Fig. 2.

The percentage concentration of the individual trienoic acids determined by GLC in the low and high trienoic acid samples are shown in Fig. 3.

\footnotetext{
* Data available from K.J.K.
}

It was found that only one trienoic acid, the C. $20: 3 \omega 9$ isomer, increased consistently. In all but one of the high trienoic acid samples, the concentration of this isomer was more than the mean in the low trienoic acid samples plus twice their standard deviation. There was no increase in any other trienoic acid which could account for the difference in total trienoic acid concentrations between the two groups.

The increase of this C.20:3 39 isomer in comparison to the neighbouring C. $20: 3 \omega 6$, or arachidonic acid was an immediately obvious feature in the GLC traces of the high trienoic acid samples, as shown in Fig. 4.

It appears that the increase in trienoic acid was due to the particular isomer (C.20:3 39$)$ synthesized in vivo from oleic acid (Fulco and Mead, 1959), and not to any of the C. 18 or C. 20 trienoic acids ( $\omega 3$ or $\omega 6)$ in the linoleic or linolenic essential fatty acid pathways (Mead, 1968).

\section{The type of abnormal fatty acid composition}

The fatty acid compositions of the low and high (abnormal) trienoic acid groups of samples are shown in Table 3.

GLC traces of samples with the low, intermediate and high trienoic acid values are compared in Fig. 5.

The increase of C. $20: 3 \omega 9$ acid in the high trienoic samples were associated with a higher percentage of C.16 and C.18 monoenoic acids (palmitoleic and oleic) but with a marked reduction in the concentration of linoleic acid. This resulted in the oleic : linoleic ratio increasing from 0.46 to $0.71 \quad(P<0.01)$ and explained the higher monoenoic to dienoic acid ratios found by plate chromatography (Table 2). 


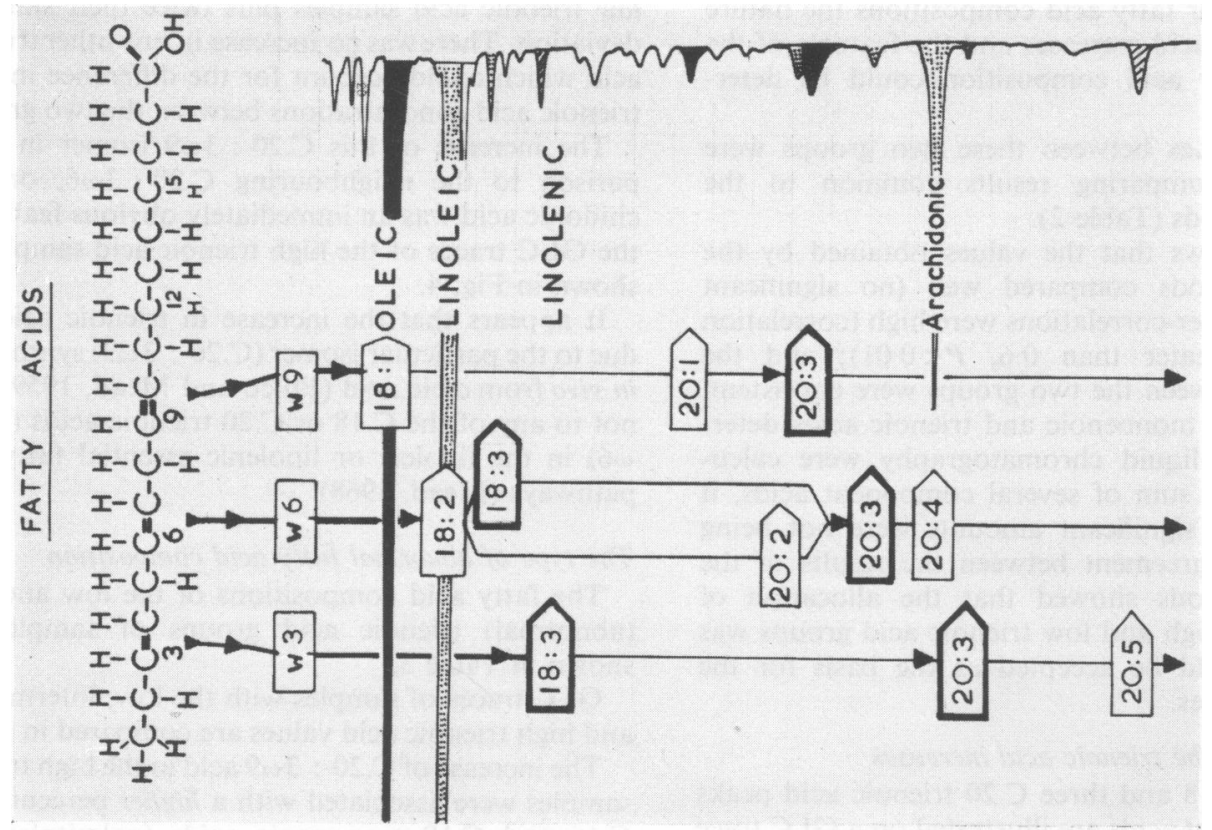

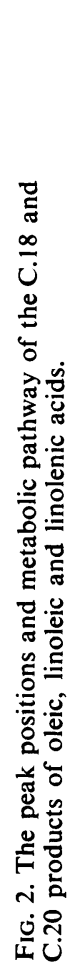

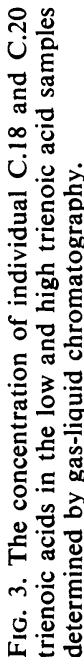

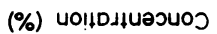

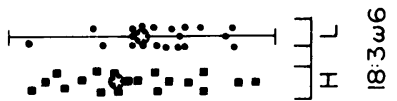

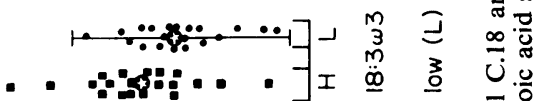

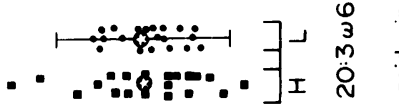

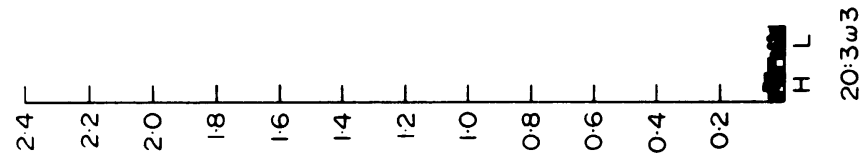

نे

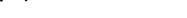




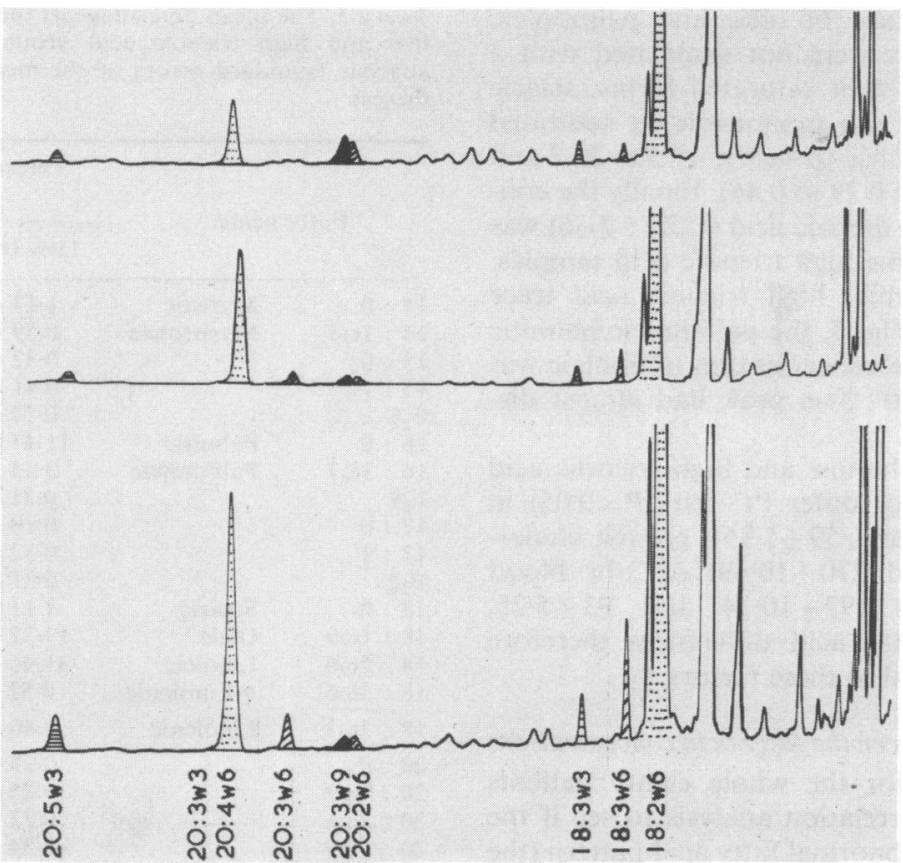

FIG. 4. A comparison of traces from low to high trienoic acid samples illustrating relative increase of the C.20: $3 \omega 9$ trienoic acid in comparison with the C.20 : $3 \omega 6$ and arachidonic acid peaks.

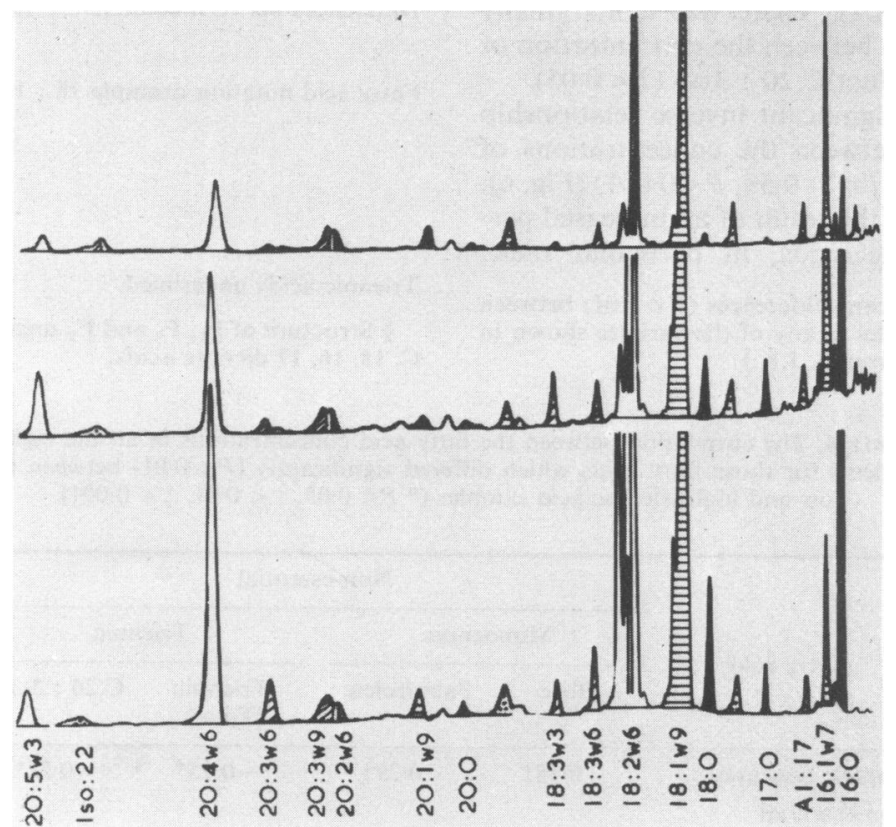

FIG. 5. A comparison of GLC traces from samples with low (bottom), intermediate, and high (top) trienoic acid concentrations. 
The higher percentage of oleic and palmitoleic monoenoic fatty acids were not associated with a corresponding rise in their saturated forms, stearic and palmitic, so that the monoenoic to saturated ratios also increased (oleic to stearic 17.5 to 25.2 and palmitoleic to palmitic $0 \cdot 29$ to $0 \cdot 46$ ). Finally the concentration of the C.20 dienoic acid (C.20:2 $2 \omega 6)$ was significantly more in the high trienoic acid samples.

In the most abnormal high trienoic acid trace shown at the top of Fig. 5, the palmitoleic/palmitic ratio was reversed, the concentration of linoleic was very low and the C.20:3w6 peak had almost disappeared.

The patients with the low and high trienoic acid concentrations did not differ ('t' test, $P>0.05$ ) in their ages $(58 \pm 1.61$ and $59 \pm 1.96)$, plasma cholesterol $(255 \pm 10 \cdot 75$ and $270 \pm 10 \cdot 49)$ or 2 -hr blood sugar concentrations $(97 \pm 10 \cdot 24$ and $93 \pm 5 \cdot 25$, respectively). The fatty acid differences therefore could not be attributed to these factors.*

\section{Interrelationships between the fatty acid concentrations}

The GLC results for the whole eighty patients were examined by correlation analysis to see if the main features of the abnormal fatty acid pattern (the significant fatty acid differences between low and high trienoic acid samples $P<0.01$ ) were linked together or were unrelated (Table 4).

The changes in the concentrations of oleic and palmitoleic acids (C.18 and C.16 monoenoic acids) correlated well $(P<0 \cdot 01)$. There was a marginally significant relationship between the concentration of oleic acid and its product C.20:3 $3 \omega 9(P<0.05)$.

A new and highly significant inverse relationship appeared, however, between the concentrations of oleic and linoleic acids (' $r$ ' $-0.58, P<0.001$ ) (Fig. 6).

This was not simply the result of an increased percentage of monoenoic acids, in particular oleic,

* There were no significant differences $(P<0.01)$ between these two groups of samples in any of the variates shown in Table 5. (Data available from K.J.K.)
TABLE 3. The mean percentage of the main fatty acids in the

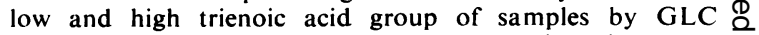
analysis (standard errors of the means are given in paren- $c$ theses)

\begin{tabular}{|c|c|c|c|}
\hline \multirow{2}{*}{\multicolumn{2}{|c|}{ Fatty acids }} & \multicolumn{2}{|c|}{$\begin{array}{l}\text { Percentage composition of } \\
\text { samples }\end{array}$} \\
\hline & & Low trienoic & High trienoic \\
\hline $\begin{array}{l}14: 0 \\
14: 1 \omega 5 \\
15: 0 \\
15: 1 \\
F_{1} \S \\
16: 0 \\
16: 1 \omega 7 \\
F_{2} \S \\
17: 0 \\
17: 1 \\
F_{3} \S \\
18: 0 \\
18: 1 \omega 9 \\
18: 2 \omega 6 \\
18: 3 \omega 6\end{array}$ & $\begin{array}{l}\text { Stearic } \\
\text { Oleic } \\
\text { Linoleic } \\
\gamma \text {-Linolenic }\end{array}$ & $\begin{array}{r}1.17(0.17) \\
0.59(0.14) \\
0.32(0.06) \\
0.41(0.07) \\
0.57(0.11) \\
11.47(0.32) \\
3.35(0.19) \\
0.31(0.05) \\
0.10(0.01) \\
0.52(0.05) \\
0.31(0.06) \\
1.11(0.09) \\
19.37(0.71) \\
41.96(1.09) \\
0.52(0.05)\end{array}$ & $\begin{array}{c}1.77(0.46) \\
0.63(0.23) \\
0.33(0.08) \\
0.36(0.09) \\
0.57(0.13) \\
10.52(0.65) \\
4.87(0.44) \dagger \\
0.56(0.08)^{*} \\
0.18(0.09) \\
0.47(0.03) \\
0.63(0.13)^{*} \\
0.97(0.07) \\
24.06(0.89)^{\ddagger} \\
33.79(1.04)_{\ddagger}^{\ddagger} \\
0.64(0.08)\end{array}$ \\
\hline $18: 3(1) 3$ & Linolenic & $0.40(0.03)$ & $0.54(0.08)$ \\
\hline $\begin{array}{l}20: 0 \\
20: 1 \omega 9 \\
20: 2 \omega 6 \\
20: 3 \omega 9\end{array}$ & & $\begin{array}{l}0.18(0.05) \\
0.25(0.08) \\
0.32(0.05) \\
0.34(0.04)\end{array}$ & $\begin{array}{l}0.31(0.07) \\
0.33(0.09) \\
0.94(0.28)^{*} \\
1.29(0.20) \ddagger\end{array}$ \\
\hline $20: 3(1) 6$ & & $0.42(0.02)$ & $0.47(0.04)$ ○ิ \\
\hline $\begin{array}{l}20: 4 \omega 6 \\
20: 3 \omega 3 \\
\end{array}$ & Arachidonic & $4.43(0 \cdot 24)$ & $4.25(0.28)$ \\
\hline $20: 5 \omega 3$ & & $0.66(0.07)$ & $0.84(0.12)$ \\
\hline
\end{tabular}

Differences between columns: ' $t$ ' test, $\quad * P<0.05$

$\dagger P<0.01$

$\pm P<0.001$

Fatty acid notation example $18: 1 \omega 9=18$ carbon atoms $: 1$ unsaturated bond $\omega 9$ unsaturated bond after 9th carbon from the methyl end of the fatty acid.

Trienoic acids underlined.

$\S$ Structure of $F_{1}, F_{2}$ and $F_{3}$ uncertain but consistent with C. 15, 16, 17 dienoic acids.

TABLE 4. The correlation between the fatty acid concentrations in all the eighty patients for those fatty acids which differed significantly $(P<0.01)$ between the low and high trienoic acid samples $(* P<0.05, \dagger<0.01, \ddagger<0.001)$

\begin{tabular}{|c|c|c|c|c|}
\hline \multirow{3}{*}{ Fatty acids } & \multicolumn{4}{|c|}{ Non-essential } \\
\hline & \multicolumn{2}{|c|}{ Monoenoic } & \multicolumn{2}{|c|}{ Trienoic } \\
\hline & Oleic & Palmitoleic & $\begin{array}{l}\text { Trienoic } \\
\text { (Total) }\end{array}$ & C. $20: 3 \omega 9$ \\
\hline Linoleic (essential) & $-0.58 \ddagger$ & $-0.29 \dagger$ & $-0 \cdot 25^{*}$ & $-0 \cdot 22^{*}$ \\
\hline $\begin{array}{l}\text { Non-essential } \\
\text { C.20: } 3 \omega 9 \\
\text { Total trienoic } \\
\text { Palmitoleic }\end{array}$ & $\begin{array}{l}+0 \cdot 23^{*} \\
+0 \cdot 24^{*} \\
+0.32 \dagger\end{array}$ & $\begin{array}{r}0.15 \\
+0.12 \\
-\end{array}$ & $\begin{array}{c}+0.29 \dagger \\
-\end{array}$ & - \\
\hline
\end{tabular}




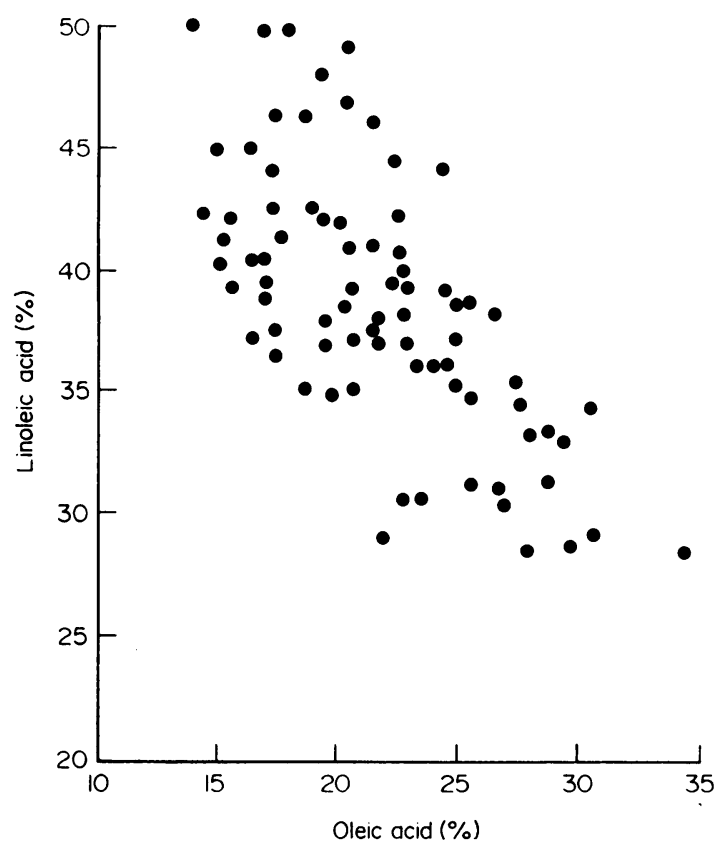

FIG. 6. The inverse relationship between oleic and linoleic acid concentrations (determined by GLC) in the eighty patients (' $r$ ' $=-0.58, P<0.001$ ),

reducing the percentage of linoleic by dilution, since parallel changes did not occur in other fatty acids. There were also no significant correlations between linoleic acid and the straight chain C.18, C.16 or C.14 saturated acids.*

The relationship between linoleic and oleic pathways (Fig. 2) appeared in the dienoic and total tri-

* Data available from K.J.K. enoic estimation of alkaline conjugation (' $r$ ' -0.30 , $P<0 \cdot 01)$. The samples which contained the most abnormal (upper) quarter of total trienoic acid values also contained over half the most abnormal (lowest) quarter of dienoic acid levels. Conversely, the most normal quarter of trienoic acid concentrations were associated with over half the most normal quarter of linoleic acid values (Fig. 7).

Finally, there was a clear inverse relationship between the total dienoic acid concentrations and the total mono-dienoic acid ratios determined by plate chromatography (Fig. 8) (correlation coefficient $-0.6254, P<0.001$ ). The six- to ten-fold change in the mono-dienoic acid ratio shows that the monoenoic acids must have increased as the concentration of dienoic acid fell.

\section{Relationship to prognosis}

The mean plasma cholesteryl fatty acid concentrations of the four prognostic groups are shown in Table 5.

Linoleic acid was the only fatty acid concentration which distinguished between the groups of patients with non-fatal or fatal infarcts, and those without symptoms of heart disease. As in a previous study (Kingsbury et al., 1969b), the incidence of acute infarction rose sharply as the linoleic acid concentration decreased ( $\chi^{2} 21 \cdot 88$ d.f.9, $P<0.01$ ) (Fig. 9).

It can be seen that $70 \%$ of the patients with linoleic concentrations under $35 \%$ had developed myocardial infarction in the first 4 years of the follow-up. Conversely none of the patients with angina, and who had not developed an infarct, had values under $35 \%$.

The oleic concentration was higher in the patients with fatal, but not in those with non-fatal infarcts,

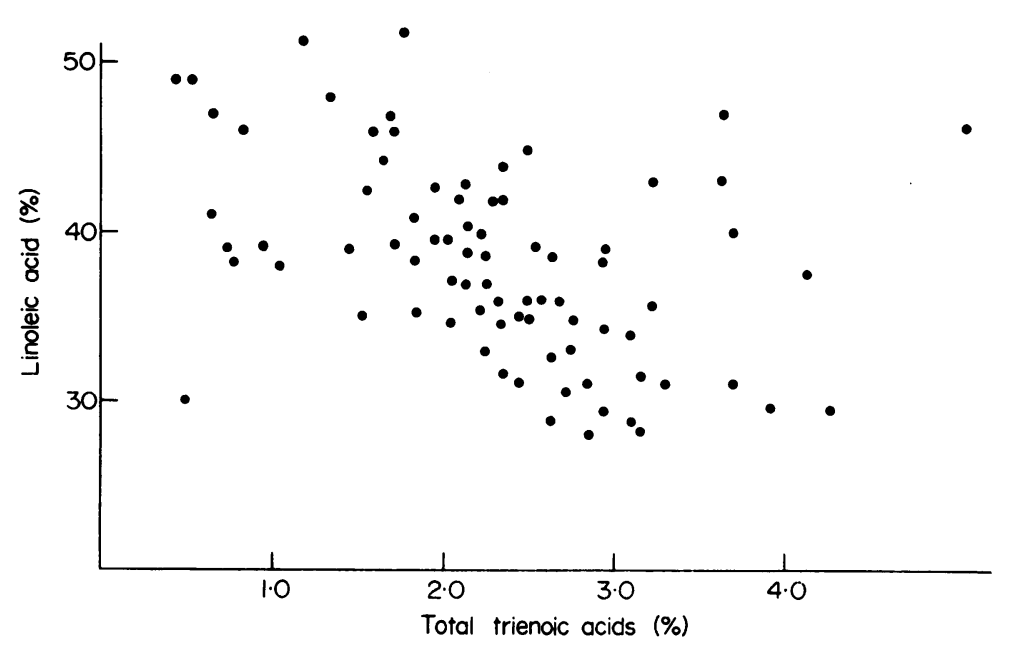

FIG. 7. A comparison of the total trienoic acid and linoleic acid concentrations in the eighty patients (determined by alkaline conjugation). 


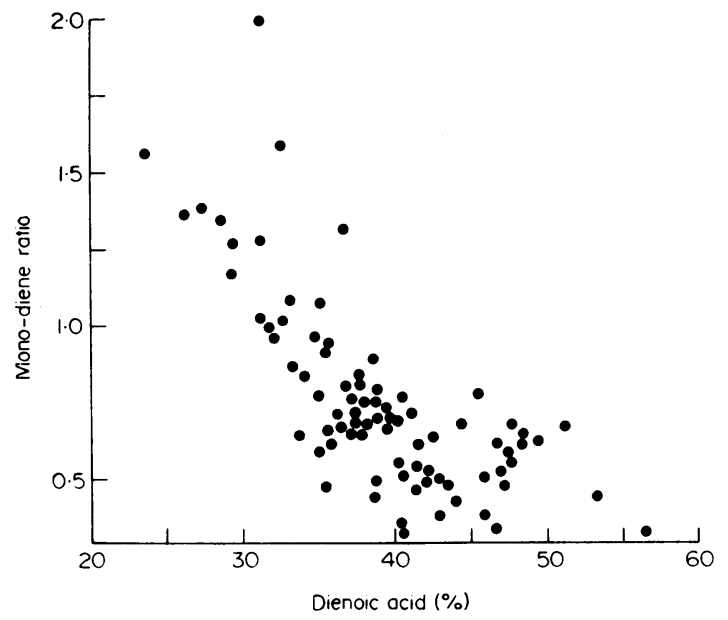

FIG. 8. The dienoic (linoleic) concentrations and the monoenoic/dienoic acid ratios (estimated by plate chromatography) in the eighty patients.

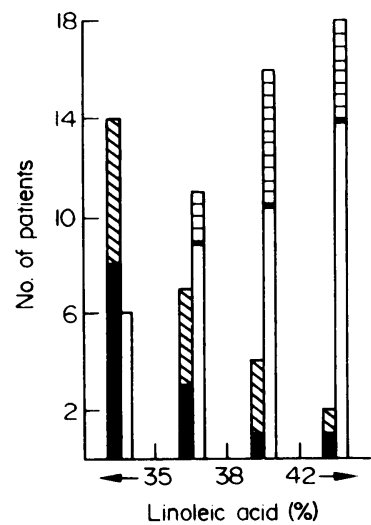

FIG. 9. The relation between the concentrations of cholesteryl linoleic and oleic acids and the proportion of patients in the four prognostic groups. $\square$, Alive and well; $\boxminus$, angina, Ac. Inf.; $\square$, Vasc. D.

TABLE 5. The mean fatty acid composition of the four prognostic groups analysed by GLC (standard error of the mean is given in brackets)

\begin{tabular}{|c|c|c|c|c|}
\hline Fatty acids & $\begin{array}{c}\text { Alive and well } \\
(40)\end{array}$ & $\begin{array}{c}\text { Angina of effort } \\
\text { (11) }\end{array}$ & $\begin{array}{l}\text { Acute infarct } \\
\text { (14) }\end{array}$ & $\begin{array}{c}\text { Vascular deaths } \\
\text { (13) }\end{array}$ \\
\hline Myristic & $1.04(0 \cdot 10)$ & $1 \cdot 12(0 \cdot 25)$ & $1.13(0.42)$ & $1.01(0.15)$ \\
\hline Myristoleic & $0.60(0.02)$ & $0 \cdot 30(0.06)$ & $0.62(0.13)$ & $0 \cdot 80(0 \cdot 24)$ \\
\hline $15: 0$ & $0.31(0.07)$ & $0.51(0.23)$ & $0.48(0.10)$ & $0.20(0.02)$ \\
\hline $15: 1$ & $0.34(0.05)$ & $0.26(0.09)$ & $0.41(0.09)$ & $0.59(0.19)$ \\
\hline$F_{1} \S$ & $0.49(0.06)$ & $0.40(0.24)$ & $0.47(0.16)$ & $0.91(0.27)$ \\
\hline Palmitic & $10.87(0.31)$ & $10.87(0.65)$ & $9.42(1.68)$ & $10 \cdot 13(0 \cdot 75)$ \\
\hline Palmitoleic & $3.92(0.24)$ & $3.51(0.25)$ & $5.04(0.56)$ & $4.69(0.45)$ \\
\hline $\mathrm{F}_{2} \S$ & $0.42(0.06)$ & $0 \cdot 37(0 \cdot 12)$ & $0.37(0.20)$ & $0.50(0 \cdot 10)$ \\
\hline $17: 0$ & $0.10(0.01)$ & $0.06(0.02)$ & $0.18(0.09)$ & $0 \cdot 28(0 \cdot 18)$ \\
\hline $17: 1$ & $0.45(0.04)$ & $0 \cdot 68(0 \cdot 11)$ & $0.50(0.06)$ & $0.54(0.03)$ \\
\hline $\mathrm{F}_{3} \S$ & $0.55(0.09)$ & $0.48(0.16)$ & $0.52(0.37)$ & $0.53(0 \cdot 10)$ \\
\hline Stearic & $1.01(0.16)$ & $0.78(0.14)$ & $0.12(0.13)$ & $0.78(0.11)$ \\
\hline Oleic & $21.09(0.43)$ & $20.16(0.88)$ & $21 \cdot 73(2 \cdot 62)$ & $24.56(1.09) \dagger$ \\
\hline Linoleic & $40.05(0.75)$ & $40.99(1 \cdot 21)$ & $36.06(1.21) \dagger$ & $31.94(2 \cdot 24) \ddagger$ \\
\hline$\gamma$-Linolenic & $0.54(0.04)$ & $0.50(0.03)$ & $0.66(0.13)$ & $0.55(0.11)$ \\
\hline Linolenic & $0.50(0.04)$ & $0.43(0.05)$ & $0.41(0.04)$ & $0.51(0.07)$ \\
\hline $20: 0$ & $0.27(0.05)$ & $0.25(0.04)$ & $0.24(0.09)$ & $0 \cdot 30(0 \cdot 12)$ \\
\hline $20: 1 \omega 9$ & $0.25(0.07)$ & $0.25(0.04)$ & $0.32(0.08)$ & $0.28(0.03)$ \\
\hline $20: 2 \omega 6$ & $0.72(0.12)$ & $0.57(0.24)$ & $0.93(0.58)$ & $0.58(0.13)$ \\
\hline $20: 3 \omega 9$ & $0.75(0.16)$ & $0.61(0.06)$ & $1 \cdot 12(0.26)$ & $1 \cdot 15(0.35)$ \\
\hline $20: 3 \omega 6$ & $0.37(0.02)$ & $0.42(0.06)$ & $0.39(0.08)$ & $0.47(0.06)$ \\
\hline Arachidonic & $4.56(0.21)$ & $4.03(0.30)$ & $4.79(0.63)$ & $3.57(0.33)^{*}$ \\
\hline $20: 3 \omega 3$ & - & - & - & 一 \\
\hline $20: 5(1) 3$ & $0.70(0.06)$ & $0.84(0.19)$ & $0 \cdot 82(0 \cdot 24)$ & $0.84(0.18)$ \\
\hline
\end{tabular}

Difference from 'Alive and well': $* P<0.05 ; \dagger P<0.01 ; \ddagger P<0.001$.

$\S$ Structure of $F_{1}, F_{2}$ and $F_{3}$ uncertain but consistent with C. 15, 16, 17 dienoic acids.

than in the group without symptoms of heart disease. The overall proportion of patients in the different prognostic groups however did not change significantly with the concentration of oleic acid ( $\gamma^{2} 12.50$ d.f.9 $P>0.05$ ). Neither palmitoleic and the trienoic acid C.20:3 39 , nor the saturated acid concentrations showed any significant differences $\stackrel{0}{\overparen{D}}$ between the prognostic groups.

The concentration of arachidonic acid, however $\tau$ (the product of linoleic acid-Fig. 2), was lower (more abnormal) in those with fatal infarcts, whereas $\bigcirc$ it did not differ between the low and high trienoic acid $\stackrel{\mathbb{Q}}{\varrho}$ 


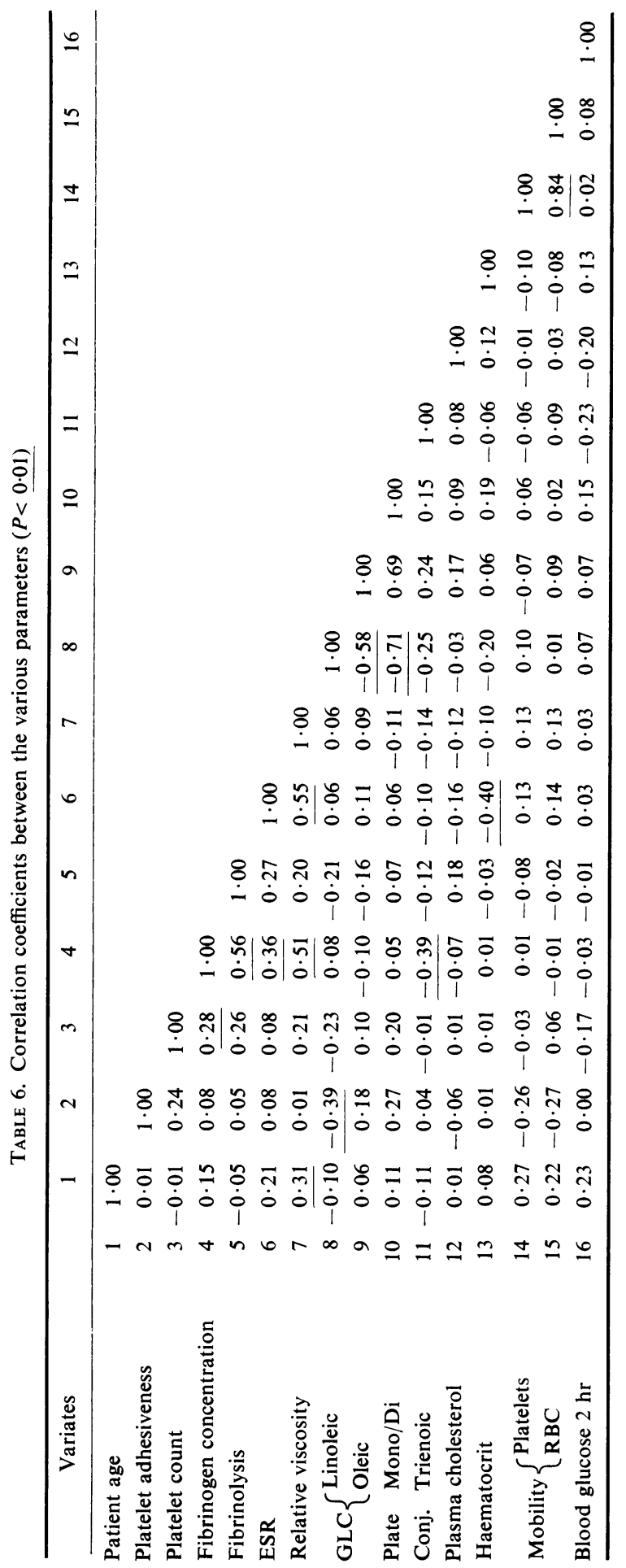


samples. It appeared that although an inverse correlation existed between linoleic and monoenoic acid concentration, the changes in the linoleic pathway still showed the clearest difference between the patients with and without myocardial infarction.

\section{Relationship with other parameters}

The relationship between the non-fatty acid parameters analysed and the main fatty acid concentrations (Table 6), and the values of the parameters for the prognostic groups (Table 7) were estimated to see if any might help to explain the different linoleic acid concentrations in the patients with and without infarction.

The fibrinogen concentrations, fibrinolysis, ESR, and relative viscosities corresponded closely $(P<$ 0.01 ), as did the electrophoretic mobilities in buffer of platelets and red cells. The high ESRs were associated with marked rouleaux formation of the red cells observed microscopically. There was an inverse relationship between ESR and haematocrit (Table 6).

Between the fatty acid concentrations and other parameters, however, only two relationships emerged: (a) an inverse relationship between linoleic acid and platelet adhesiveness (' $r$ ' $=-0.3954$, $P<0.01)$ and (b) an inverse correlation between total trienoic acid and the plasma fibrinogen concentration (' $r$ ' $=-0.3904, P<0.01$ ).

None of the non-fatty acid parameters showed significant differences between the prognostic groups except that platelet adhesiveness was marginally higher $(P<0.05)$ in those with fatal infarcts than in the patients without symptoms of heart disease (Table 7). The blood glucose levels were higher in the patients with infarcts, but the differences between the prognostic groups were not statistically significant $\frac{2}{\infty}$ $(P>0.05)$.

The inter-relationship between these non-fatty $\stackrel{c}{\Rightarrow}$ acid parameters will be discussed in more detail else- $\underset{\sim}{\stackrel{(}{\rightarrow}}$ where; they are reported here to show that out of the $\frac{\overrightarrow{0}}{\mathrm{C}}$ parameters examined and the various fatty acids, the $\frac{0}{\sigma}$ concentration of linoleic acid still exhibited a par- $\overline{\bar{N}}$ ticularly clear relationship with the incidence of myo- $\mathbb{D}$ cardial infarction. This did not seem explainable in 0 terms of the other parameters, excepting possibly for ${ }^{\text {S }}$ a marginal relationship with platelet adhesiveness.

The marked inverse relationship between the oleic and linoleic acid concentrations indicated that their $\omega_{\sigma}$ changes were in some way linked together.

\section{Discussion}

The analyses show that the high trienoic acid concentrations were caused by an increase in a single of trienoic acid, the C.20:3 39 known to be synthesized $A$

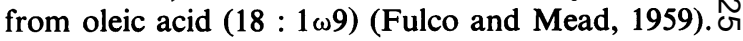
There was no consistent increase in the C.20 or C.18음 trienoic acid intermediates of linoleic and linolenic acid metabolism (Fig. 2).

The similarity in the characteristics of these patients with previous series (Kingsbury, 1966, 1968, $\overrightarrow{0}$ 1971; Kingsbury et al., 1969a, b) suggests that the results would not be unusual for this type of patien. It is believed that the range of disease extent and ty and biochemistry would have exposed different types of trienoic acid increases if they had existed. It appears therefore that the increased trienoic acid $\stackrel{\circ}{\mathbb{Q}}$ concentrations did not arise from a blocked step in $\underset{\rightarrow}{\Rightarrow}$ either the linoleic or linolenic essential fatty acid $\overrightarrow{\vec{B}}$ pathways. Since the C.20:3 39 isomer has a high 3 turnover rate (Mohrhauer and Holman, 1965), its accumulation in these patients would seem to result

TABLE 7. General parameters of the four prognostic groups (means with their standard errors in brackets)

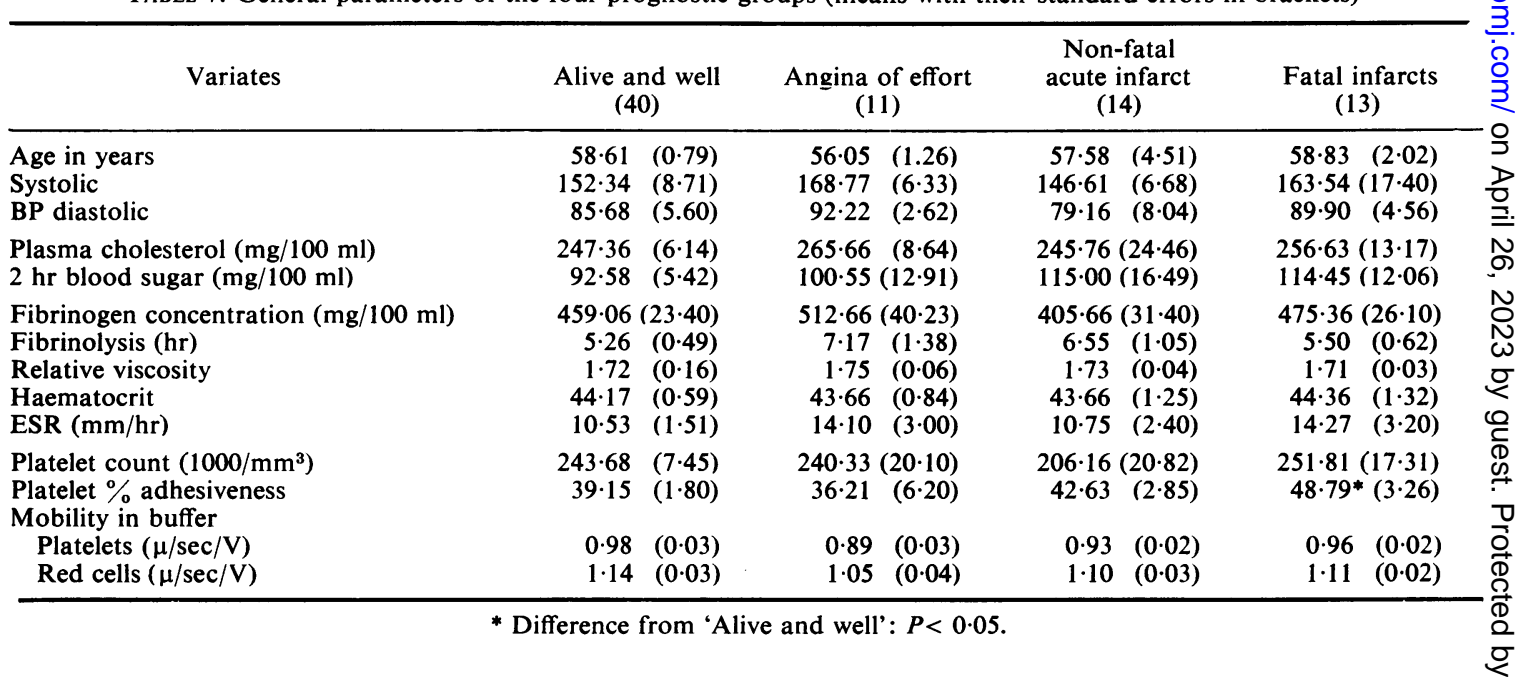


from an increased formation of oleic acid products.

Fulco and Mead (1959) showed that the C.20:3 39 was the specific trienoic acid which increased in animals deficient in essential fatty acids. Its appearance has been accepted as an early sign of EFA deficiency (Holman, 1960) and its concentration as an assay of an animal's 'EFA status' (Holman, 1968, 1970). The increased ratio of C. $20: 3 \omega 9$ to arachidonic acid, an obvious feature of the high trienoic acid samples reported here, has also been used to estimate EFA deficiency (Holman, 1968, 1970). The accumulation of C.20:3 39 therefore raises the question of whether an essential fatty acid deficiency could exist in these patients.

The cholesteryl ester fatty acids are derived from the $\beta$ position of phospholipids (Glomset, 1962) by a generally non-specific transferase (Portman and Sugano, 1964), so that changes in the composition of the cholesteryl esters reflect underlying changes in the phospholipids. One exception is that relatively little of an increased phospholipid C.20:3 39 (where the concentration is particularly high in EFA deficiency-Holman, 1968) is transferred to the cholesteryl ester (Sand and Schlenk, 1968). Hence the abnormal cholesteryl ester pattern would seem likely to understate rather than over-emphasize the extent of the C. $20: 3 \omega 9$ accumulation.

The main features of the abnormal fatty acid pattern in addition to the specific increase of C. 20 : $3 \omega 9$ and decrease in linoleic acid, were raised amounts of oleic and palmitoleic acids. These changes and the increased ratio of arachidonic to linoleic acid (Mead, 1968) are also found in animals deficient of essential fatty acids (Holman, 1968, 1970).

The percentage of straight chain C.18 and C.16 saturated acids, stearic and palmitic, respectively, did not increase with their monoenoic forms (oleic and palmitoleic). This implies an increase of C.18 and C.16 mono-unsaturase activity which again is a feature of EFA deficiency (Allmann and Gibson, 1965). The observed rise in oleic and palmitoleic acids is also consistent with the increased synthesis of fatty acids found in EFA deficient animals (Allmann, Hubbard and Gibson, 1965).

Finally, although there does not appear to be any published work which explains the increase of C. $20: 2 \omega 6$, the slower initial elongation of linoleic acid $(18: 2 \longrightarrow 20: 2 \omega 6)$ is favoured at the expense of the usually faster initial desaturation $(18: 2 \longrightarrow 18: 3 \omega 6)$ in EFA deficient animals (Marcel, Chistiansen and Holman, 1968). Whether this could result in an accumulation of C. $20: 2 \omega 6$ remains to be determined.

Thus whereas the composition of the main fatty acids in the low trienoic acid samples was similar to that published for 'normal' subjects (Schrade et al.,
1960; Smith, 1962; Goodman, 1965), the high trienoic abnormal fatty acid pattern was specifically and generally consistent with an EFA deficiency.

It has seemed difficult to accept that the low linoleic concentrations result simply from an absolute deficiency of EFA when they existed in patients who were known to have varied and comprehensive diets.

Animal studies (reported by Holman, 1968, 1970), however, show that the concentration of linoleic acid in vivo is influenced by various factors, particularly the calorie intake. In many animal species (Holman, 1964, 1968, 1970) and children (Wiese et al., 1958) the calorie intake had to be less than 25 to 50 times the calorie value of the dietary linoleic to prevent a reduction in linoleic, and an increase in trienoic acid concentrations.

On this basis and taking an average linoleic intake of approximately $8 \mathrm{~g}$ (Hudson, 1965) the linoleic acid concentrations might fall if the total calories exceeded about 2500/day. There appears some evidence to support this possibility. When students were given diets of $3000-3600$ calories, without changing their activities or living conditions, their plasma cholesteryl linoleic acid concentrations fell rapidly from normal to 'atheromatous' levels unless supplements of linoleic acid were also given (Kingsbury et al., 1962a).

In adult man, the calorie balance would also be modified by different physical (Passmore and Durnin, 1955; Astrand and Rodahl, 1970; Kingsbury, 1972), and hormonal activities (for example, degrees of hyper- and hypo-thyroidism). Furthermore, as in animals the requirement for EFA could vary with the protein and carbohydrate intake (Inkpen, Harris and Quackenbush, 1969; Brenner, 1971), androgen, insulin, and steroid levels (Lyman, 1968), hypercholesterolaemia (Holman, 1968) and perhaps with 'stress' (Smith and Sodergren, 1966), high calcium and low zinc (Holman, 1968) or low magnesium diets (Hill et al., 1957). Hence it appears that if the dietary EFA was marginally adequate, various nutritional and metabolic factors could have precipitated the low linoleic acid concentrations observed in the patients.

In animals, many factors which increase the linoleic acid requirement also increase the formation of oleic from stearic, and palmitoleic from palmitic acid by stimulating $\Delta 9$ desaturase activity; for example, overfeeding (Gurr, 1973), carbohydrate diets (Inkpen et al., 1969), insulin (Brenner, 1971) but not proteins or saturated fats (Inkpen et al., 1969; Gomez Dumm, Alamiz and Brenner, 1970). Low linoleic acid concentrations facilitate this since the inhibition by EFA of fatty acid synthesis (Allmann, Hubbard and Gibson, 1965) and $\Delta 9$ desaturase activity (Mead, 1968; Brenner, 1971) is then reduced. In contrast, the requirement for EFA fatty acid synthesis, and 
$\Delta 9$ desaturase activity, are decreased by fasting (Inkpen et al., 1969; Gomez Dumm et al., 1970; Holman, 1968, 1970).

Thus the concentration of monoenoic and essential fatty acids are affected-usually conversely-by nutritional and metabolic factors. This may explain the inverse relationship between the monoenoic and linoleic concentrations observed in the patients. This relationship appears specific and not simply the dilution of one by the other, since proportional changes did not occur in the saturated or other unsaturated fatty acids.

In animals an increase of dietary oleic acid (ethyloleate) precipitated the symptoms of an EFA deficiency and a high mortality, whereas the animals' health was unaffected by large amounts of saturated fats (Dhopeshwarkar and Mead, 1961). Similarly an increase of oleic acid in vivo (Dhopeshwarkar and Mead, 1961), in tissues (Lowry and Tinsley, 1966), or in sub-cellular fractions (Mead, 1968; Brenner, 1971) interfered with EFA metabolism by competing for the necessary desaturases. These were unaffected by the saturated acids (Brenner, 1971). It appeared that the saturated fats had no anti-EFA effect other than a non-specific contribution to calories (Holman, 1964). Thomasson et al. (1966) also found that dietary hydrogenated saturated fats produced no abnormal changes in a wide variety of parameters in rats including coagulability, platelet adhesiveness, and post mortem findings. Oleic acid (triolein), however, caused a high plasma cholesterol level and high mortality (Thomasson et al., 1960).
These toxic effects are associated with the replacement of EFA by other fatty acids, in the blood and tissue lipids-including those necessary for enzyme and membrane function (Klein and Johnson, 1954; Tupule and Williams, 1955; Leven, Johnson and Albert, 1957; Fleischer et al., 1962; Johnson and Ito, 1965; De Pury and Collins, 1966; Green and Baum, 1969). The monoenoic acids and their products, unlike the saturated acids, can additionally impede the metabolism of the remaining linoleic and linolenic acids (Mead, 1968; Holman, 1968) and displace them from the $\beta$ position of the phospholipids (Leat, 1962). It seems likely that these competitions could be more effective when the monoenoic acids are synthesized within the cells, than when they are fed by mouth in which case only a small proportion may reach the intracellular sites of desaturation and esterification. There is some evidence that the changed compositions would then affect at least coagulation and thrombosis since the dioleyl ester was the most coagulant phosphatidyl ethanolamine (Billimoria, Irani and Maclagen, 1965) and saturation of the phospholipid tissue factor reduced its coagulant activity (Nemerson, 1968). In fact, Evans and Irvine (1966) reported a relationship between low linoleic acid concentrations, platelet adhesive- $\varnothing$ ness and arterial graft thrombosis. It seems possible that these changes at least contributed to the associa tion between the low linoleic acid concentration,? aorto-iliac/femoro-popliteal occlusion and myocardial infarction reported previously (Kingsbury $e t$ al., 1969a, b).

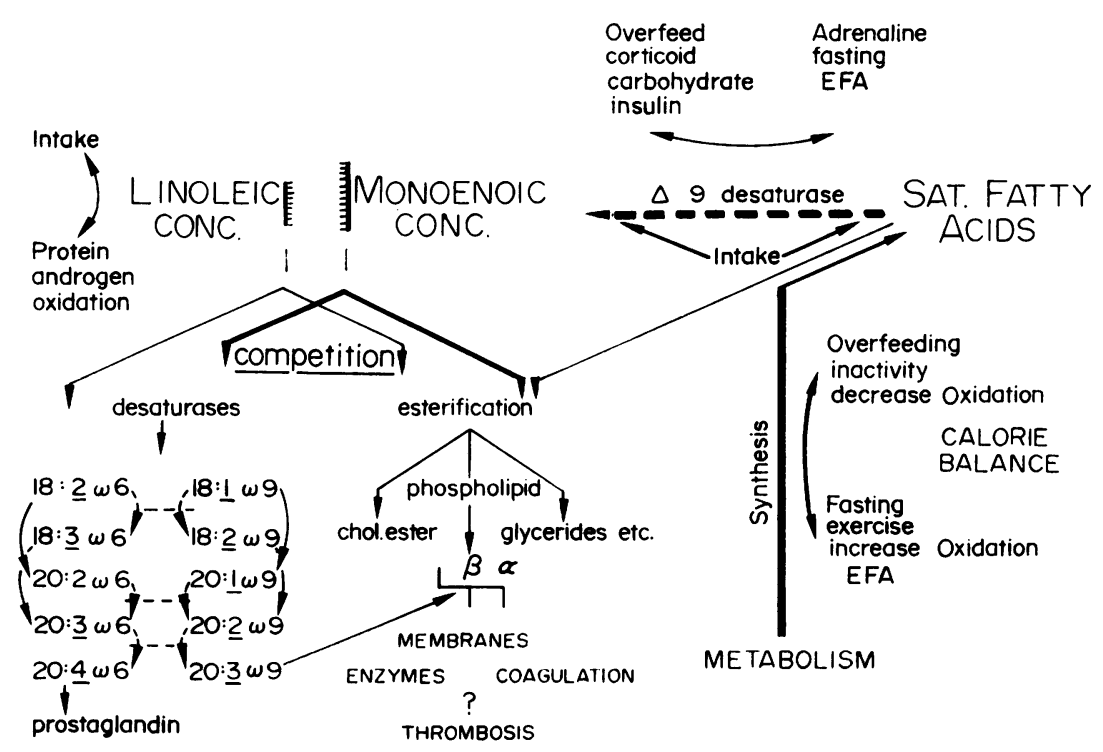

FIG. 10. A tentative illustration of factors affecting the linoleic-oleic balance. 
Finally, as the desaturation of oleic acid to C.20: $3 \omega 9$ is normally inhibited by the much stronger desaturase affinity of linoleic or linolenic acids and their products (Mead, 1968), the pronounced fall of linoleic concentration in some patients, and the accumulation of C. $20: 3 \omega 9$ itself, suggests that at least an element of EFA inadequacy existed. It appears therefore that the abnormal fatty acid composition resulted from an increased monoenoic 'drive' (fatty acid synthesis and monounsaturase activity) - and perhaps the use of EFA-with which the intake of EFA had not kept pace.

In animals the balance between EFA and monoenoic 'pools' is influenced in the former by intake, oxidation, polyunsaturase activity and in the latter by intake, oxidation, fatty acid synthesis and monounsaturase activity, varied by calorie balance, other aspects of nutrition and metabolism (Holman, 1968; Inkpen et al., 1969; Gomez Dumm et al., 1970; Brenner, 1971; Gurr, 1973). Since many of the factors which increase their monoenoic to linoleic acid ratio (e.g. excessive calories, high insulin levels, diabetes, hypocholesterolaemia, androgens and stress) are widely associated with human atherosclerosis (Leading Article, British Medical Journal, 1973), the question arises of whether the EFA-fatty acid, particularly monoenoic, balance is one link between these factors and the pathology of the occlusive disease.

These interrelationships are tentatively outlined in Fig. 10. They seem to provide a common basis for both fat and carbohydrate theories of atherosclerosis (McGandy, Hegsted and Stare, 1967) and may explain the low incidence of atherosclerosis in the saturated fat-eating Masai tribe, since their low calorie balance (Mann et al., 1972) would inhibit both fatty acid synthesis and monounsaturase activity (Brenner, 1971; Gurr, 1973).

The interrelationships appear to open up the consideration of EFA function not simply in terms of intake but in relation to whole nutrition and metabolism. The relative contribution of the various factors to the low linoleic concentrations in the patients now needs to be determined.

\section{Acknowledgments}

The study would not have been possible without the willing help of the patients, their relatives, the many doctors and hospitals concerned. The patients were first seen in the Surgical Unit, St Mary's Hospital, London, W.2. We would like to thank Professor W. T. Irvine and the Unit, and Professor A. Neuberger and the Chemical Pathology Department where the analyses continued; the Medical Records Department at St Mary's Hospital, and Mrs E. Byard, Miss June Tackley and Mrs E. Jullien for considerable help in the follow-up. The analyses were made possible by the supply of standards from Professor Van Dorp, Unilever Laboratories, Vlaardingen and the ready assistance and modification of apparatus by the staff of Perkin Elmer Ltd, particularly A. Pike, and Infotronics Ltd, and J. Tatlow. We would like to thank the British Nutrition Foundation but particularly Unilever Ltd for their long and generous support of the work.

\section{References}

Allmann, D.W. \& Gibson, D.M. (1965) Fatty acid synthesis during early linoleic acid deficiency in the mouse. Journal of Lipid Research, 6, 51.

AllmanN, D.W., Hubbard, D.D. \& Gibson, D.M. (1965) Fatty acid synthesis during fat-free refeeding of starved rats. Journal of Lipid Research, 6, 63.

Antonini, F.M., Bucalossi, A., Petruzzi, E., Simon, I.R., Morini, P.L. \& D'Alessandro, A. (1969) Fatty acid composition of adipose tissue in normal, atherosclerotic and diabetic subjects. Atherosclerosis, 11, 279.

Astrand, P.O. \& Rodahl, K. (1970) A Textbook of Work Physiology. McGraw-Hill Book Company, New York.

Bangham, A.P., Flemans, R., Heard, D.H. \& Seaman, G.V.S. (1958) An apparatus for microelectrophoresis of small particles. Nature, 182, 642.

Billimoria, J.D., Irani, V.J. \& Maclagen, N.F. (1965) Phospholipid fractionation and blood clotting. Journal of Atherosclerosis Research, 5, 90.

Blackburn, H., Keys, A., Simonson, E., Rautaharjo, P. \& PunsaR, S. (1960) The electrocardiogram in population studies. Circulation, 21, 1160.

BrenNer, R.R. (1971) The desaturation step in the animal biosynthesis of polyunsaturated fatty acids. Lipids, 6, 567.

De PuRY, C.G. \& Collins, F.D. (1966) The influence of fatty acid composition on the restoration of succinate-cytochrome $\overline{\mathbf{c}}$ reductase activity by phospholipids in extracted mitochondria. Chemistry and Physics of Lipids, 1, 20.

DhOPEShWARKAR, G.A. \& MEAD, J.F. (1961) Role of oleic acid in the metabolism of essential fatty acids. Journal of American Oil Chemists Society, 38, 297.

Evans, G. \& IRvine, W.T. (1966) Long-term arterial-graft patency in relation to platelet adhesiveness, biochemical factors and anticoagulant therapy. Lancet, ii, 353.

Findlay, A. (1954) Practical Physical Chemistry. Eighth edition. Longmans, Green, London.

Fleischer, S., Brierley, G., Klouwen, H. \& SlautterBACK, D.B. (1962) The role of phospholipids in electron transfer. Journal of Biological Chemistry, 237, 3264.

FulCo, A. \& MeAD, J.F. (1959) Metabolism of essential fatty acids. VIII. Origin of $5,8,11$ - eicosatriendic acid in the fat deficient rat. Journal of Biological Chemistry, 234, 1411.

Gallimore, M.J. (1967) Effect of diluents on blood clot lysis. Journal of Clinical Pathology, 20, 234.

GLOMSET, J.A. (1962) The mechanism of the plasma cholesterol esterification reaction: plasma fatty acid transferase. Biochimica et Biophysica Acta, 65, 128.

Gomez Dumm, N.T. DE, Alamiz, M.J.T. de \& Brenner, R.R. (1970) Effect of diet on linoleic acid desaturation and on some enzymes or carbohydrate metabolism. Journal of Lipid Research, 11, 96.

Goodman, DeWITt S. (1965) Cholesterol ester metabolism. Physiological Reviews, 45, 747.

GreEN, D.E. \& BAUM, H. (1969) Energy and the Mitochondrion. Academic Press, New York.

GuRR, M.I. (1973) Personal communication.

Heard, D.H. \& Seaman, G.V.S. (1960) The influence of pH and ionic strength on the electrokinetic stability of the human erythrocyte membrane. Journal of General Physio$\log y, 43,635$.

Heffernan, A.G.A. (1963) The fatty acid composition of human adipose tissue. Clinical Science, 25, 423.

Henly, A.A. (1957) The determination of serum cholesterol. Analyst, 82, 286.

Hill, E.G., Warmanen, E.L., Hayes, H. \& Holman, R.T. (1957) Effects of essential fatty acid deficiency in young swine. Proceedings of the Society for Experimental Biology and Medicine, 95, 274. 
Hirsh, J., McBride, J.A. \& Wright, H.P. (1966) Platelet adhesiveness: A comparison of the rotating bulb and glass-bead column methods. Thrombosis et Diathesis Haemorrhagica, 16, 100.

Holman, R.T. (1960) The ratio of trienoic : tetraenoic acids in tissue lipids as a measure of essential fatty acid requirement. Journal of Nutrition, 70, 405.

Holman, R.T. (1964) Nutritional and metabolic interrelationships between fatty acids. Federation Proceedings, 23, 1062.

Holman, R.T. (1968) Essential fatty acid deficiency. In: Progress in the Chemistry of Fats and other Lipids, IX, Part 2, p. 275. Pergamon Press, London.

Holman, R.T. (1970) Biological activities of and requirements for polyunsaturated acids. In: Progress in the Chemistry of Fats and other Lipids, IX, Part 5, p. 607. Pergamon Press, London.

Holman, R.T. \& HaYes, H. (1958) Determination of polyunsaturated acids in lipids of plasma and tissue. Analytical Chemistry, 30, 1422.

Hudson, B.J. (1965) (Personal communication to K. J. Kingsbury) In: 'The essential fatty acids and human atheroma'. Geriatrics, 20, 554.

Huggett, A.St.G. \& Nixon, D.A. (1957) Use of glucose oxidase, peroxidase, and o-dianisidine in determination of blood and urinary glucose. Lancet, ii, 368.

InKPen, C.A., HARris, R.A. \& QuACKenbush, F.W. (1969) Differential responses to fasting and subsequent feeding by microsomal systems of rat liver: 6- and 9- desaturation of fatty acids. Journal of Lipid Research, 10, 277.

JoHnson, R.M. \& ITO, T. (1965) Effects of a nutritional deficiency of unsaturated fats on the distribution of fatty acids in rat liver mitochondrial phospholipids. Journal of Lipid Research, 6, 75.

KingSBURY, K.J. (1966) The relation between glucose tolerance and atherosclerotic vascular disease. Lancet, ii, 1374.

KINGSBURY, K.J. (1968) Glucose tolerance, age and atherosclerosis. Postgraduate Medical Journal, 44, 944.

KingSBURY, K.J. (1969) Concept of human atherosclerosis. Nature, 224, 146.

KingSBURY, K.J. (1971) Relation of ABO blood-groups to atherosclerosis. Lancet, i, 199.

KINGSBURY, K.J. (1972) Assessment of fitness. In: Sport in the Modern World. Chances and Problems. P. 453. Scientific Congress XXth Olympiad, Munich 1972, Springer Verlag: Berlin.

Kingsbury, K.J., Heyes, T.D., Morgan, D.M., Aylott, C., Burton, P., Emmerson, R. \& Robinson, P.J.A. (1962a) The effect of dietary changes in the fatty acid composition of normal human depot fat. Biochemical Journal, 84, 124.

Kingsbury, K.J., Morgan, D.M., Aylott, C., Burton, P., EMmerSON, R. \& RoBINSON, P.J. (1962b) A comparison of the polyunsaturated fatty acids of the plasma cholesteryl esters and subcutaneous depot fats of atheromatous and normal people. Clinical Science, 22, 161.

Kingsbury, K.J., Morgan, D.M., Stovold, R. \& Brett, C.G. (1969a) The relationships between plasma cholesteryl polyunsaturated fatty acids, age and atherosclerosis. Postgraduate Medical Journal, 45, 591.

Kingsbury, K.J., Morgan, D.M., Stovold, R., Brett, C.G. \& ANDERSON, J. (1969b) Polyunsaturated fatty acids and myocardial infarction. Lancet, ii, 1325

Kingsbury, K.J., Paul, S., Crossley, A. \& Morgan, D.M. (1961) The fatty acid composition of human depot fat Biochemical Journal, 78, 541.

KLeiN, P.D. \& Johnson, R.M. (1954) Phosphorus metabolism in unsaturated fatty acid-deficient rats. Journal of Biological Chemistry, 211, 103.

LEADING ARTICLE (1973) The odds on getting a coronary. British Medical Journal, ii, 375.
LEAT, W.M.F. (1962) Plasma fatty acids of pigs reared on differing levels of linoleic acid. Biochemical Journal, 83, 37P.

Levin, E., Johnson, R.M. \& Albert, S. (1957) Mitochondrial changes associated with essential fatty acid deficiency in rats. Journal of Biological Chemistry, 228, 15.

LEWIS, B. (1958) Composition of plasma cholesterol ester. In relation to coronary artery disease and dietary fat. Lancet, ii, 71 .

LOWRY, R.R. \& TINSLEY, J.T. (1966) Oleic and linoleic acid interaction in polyunsaturated fatty acid metabolism in the rat. Journal of Nutrition, 88, 26.

LYMAN, R.L. (1968) Endocrine influences on the metabolism of polyunsaturated fatty acids. In: Progress in the Chemistry of Fats and other Lipids, IX, Part 2, p. 193. Pergamon Press, London.

McGandy, R.B., Hegsted, D.M. \& Stare, F.J. (1967) Dietary fats, carbohydrates, and atherosclerotic vascular disease. New England Journal of Medicine, 277, 186.

ManN, G.V., Spoerry, A., Gray, M. \& Jarashow, D. (1972) Atherosclerosis in the Masai. American Journal of Epidemiology, 95, 26.

Marcel, Y.L., Chistiansen, K. \& Holman, R.T. (1968) The preferred metabolic pathway from linoleic acid to arachidonic acid in vitro. Biochimica et Biophysica Acta, 164, 25.

MEAD, J.F. (1968) The metabolism of the polyunsaturated fatty acids. In: Progress in the Chemistry of Fats and other Lipids, IX, Part 2, p. 161. Pergamon Press, London.

Mohrhauer, H. \& Holman, R.T. (1965) Tracer experiments to assess metabolic conversions of polyunsaturated fatty acids. Journal of American Oil Chemists Society, 42, 639.

NEMERSON, Y. (1968) The phospholipid requirement of tissue factor in blood coagulation. Journal of Clinical Investigation, 47, 72.

Passmore, R. \& DURnin, J.V.G.A. (1955) Human energy expenditure. Physiological Reviews, 35, 801.

PODMORE, D.A. (1959) Rapid turbidimetric methods for the determination of plasma fibrinogen. Clinica Chimica Acta, 4, 242.

Portman, O.W. \& Sugano, M. (1964) Factors influencing the level and fatty acid specificity of the cholesterol esterification activity in human plasma. Archives of Biochemistry and Biophysics, 105, 532.

SAND, D.M. \& SChlenk, H. (1968) The distribution or odd numbered essential and other polyenoic fatty acids in rat liver lipids. Biochimica et Biophysica Acta, 164, 598.

Schrade, W., Böehle, E. \& Biegler, R. (1960) Humoral changes in arteriosclerosis. Investigations on lipids, fatty acids, ketone bodies, pyruvic acid, lactic acid, and glucose in the blood. Lancet, ii, 1409.

SMITH, E.B. (1962) Lipids carried by Sf 0-12 lipoprotein in normal and hypocholesterolaemic serum. Lancet, ii, 530.

Smith, J.A. \& Sodergren, A. (1966) Oxidative capacity of mitochondria isolated from stressed essential fatty-acid deficient rats. Federation Proceedings, 25, 673.

Thomasson, H.J., vaN BeERs, G.J., GotTenbos, J.J., DeIongh, H., Keppler, J.G. \& Sparreboom, S. (1960) The influence of fats in cholesterol metabolism of the rat. Biochemistry of Lipids, p. 194. Pergamon Press, Oxford.

Thomasson, H.J., Gottenbos, J.J., Kloeze, J. \& Vles, R.O. (1966) Nutritional evaluation of hydrogenated fats. Proceedings of the Nutrition Society, 25, 1.

Tupule, P.G. \& Williams, T.N. (1955) Study of the role of essential fatty acids in liver metabolism. Journal of Biological Chemistry, 217, 229.

Wiese, H.F., Hansen, A.E. \& Adam, D.J.D. (1958) Essential fatty acids in infant nutrition. Linoleic acid requirement in terms of serum di, tri, and tetraenoic acids. Journal of Nutrition, 66, 345. 